\title{
Influence of Personality on Satisfaction with Mobile Phone Services
}

\author{
RODRIGO DE OLIVEIRA, MAURO CHERUBINI, and NURIA OLIVER, Telefonica Research
}

We propose a conceptual model that explains the relationship between the users' personality profile and their satisfaction with basic mobile phone services (calls, messages, and simple GPRS/3G services). The model captures direct and indirect effects on satisfaction by means of two variables: actual mobile phone usage and perceived usability of the related services. We empirically validate the model with data gathered from 603 customers of a telecommunication operator, and find that: (1) extroversion, conscientiousness, and intellect have a significant impact on customer satisfaction-positively for the first two traits and negatively for the latter; (2) extroversion positively influences mobile phone usage; and (3) extroversion and conscientiousness positively influence the users' perceived usability of mobile services. Interestingly, usability has the strongest positive impact on satisfaction, whereas mobile phone usage has a negative impact on satisfaction. We discuss key findings of this model and propose several implications for the design of mobile phone services.

Categories and Subject Descriptors: H.1.2 [Models and Principles]: User/Machine Systems-Human Factors; J.4 [Social Behavioral Sciences]: Psychology

General Terms: Design, Experimentation, Human Factors, Measurement, Theory

Additional Key Words and Phrases: Big five, structural equation modeling, usability

\section{ACM Reference Format:}

de Oliveira, R., Cherubini, M., and Oliver, N. 2013. Influence of personality on satisfaction with mobile phone services. ACM Trans. Comput.-Hum. Interact. 20, 2, Article 10 (May 2013), 23 pages.

DOI: http://dx.doi.org/10.1145/2463579.2463581

\section{INTRODUCTION}

Mobile phones are today's de facto personal computers: with over 4 billion users, mobile phones account for more than five times the number of PCs worldwide. They are less expensive, smaller, and lighter than most desktop PCs, laptops, and tablets, while increasingly powerful in terms of computation, sensing, and interaction capabilities.

A driver for the sustained consumption of mobile phone services is customer satisfaction, which is one of the measurements of user experience, and a key concept used in marketing to measure how products and services meet or surpass customer expectations. Differences in customer satisfaction over time can warn companies of problems affecting sales and profitability. These problems are often identified by validating theory-grounded conceptual models with empirical data that quantifies the relationship between customer satisfaction and other concepts, such as user behavior and quality of services [Turel and Serenko 2006]. In Human-Computer Interaction (HCI), user satisfaction is also one of the top measurement priorities in user-centered design [Rogers et al. 2011].

Telefonica Research participates in the Torres Quevedo subprogram (MICINN), cofinanced by the European Social Fund, for researchers recruitment.

M. Cherubini is currently affiliated with Google Inc., Zurich, Switzerland.

Authors' addresses: R. de Oliveira (corresponding author), email: oliveira@tid.es; M. Cherubini, email: mauro. cherubini@acm.org; and N. Oliver, nuriao@tid.es; Telefonica Research, Barcelona, Spain.

Permission to make digital or hard copies of part or all of this work for personal or classroom use is granted without fee provided that copies are not made or distributed for profit or commercial advantage and that copies show this notice on the first page or initial screen of a display along with the full citation. Copyrights for components of this work owned by others than ACM must be honored. Abstracting with credit is permitted. To copy otherwise, to republish, to post on servers, to redistribute to lists, or to use any component of this work in other works requires prior specific permission and/or a fee. Permissions may be requested from Publications Dept., ACM, Inc., 2 Penn Plaza, Suite 701, New York, NY 10121-0701 USA, fax +1 (212) 869-0481, or permissions@acm.org.

(c) 2013 ACM 1073-0516/2013/05-ART10 $\$ 15.00$

DOI: http://dx.doi.org/10.1145/2463579.2463581 
There is evidence that suggests that personality plays a role in determining how satisfied users are with a particular mobile service. According to personality psychology, two apparently similar persons can behave differently when submitted to the same situation mostly due to differences in their personality [Paunonen and Ashton 2001; Butt and Phillips 2008]. Designers have leveraged users' personality to improve the design of interactive products [Lee and Nass 2003; Eckschlager et al. 2005; Nunes et al. 2008]. However, little work has been carried out to date towards understanding how people's personality affects their satisfaction with mobile services. Hence, we believe that there is a need for in-depth studies of how people's personality traits influence their mobile service satisfaction.

In this article, we propose a conceptual model that captures the relationship between users' personality and their satisfaction with mobile phone services. This relationship is characterized by both direct and indirect links through two additional variables (mediators): actual mobile phone usage and perceived usability of the mobile services. We validate the proposed model with data collected from 603 customers of a telecommunication operator. Our results reveal that personality plays a significant role on the three variables of study: actual phone usage, perceived usability of mobile services, and subjective satisfaction with mobile services. Hence, we believe that the design of mobile services would benefit from taking into account the user's personality.

The main contributions of this work include the following.

(1) We develop a conceptual model that captures the direct influence of the users' personality on their satisfaction with mobile phone services ${ }^{1}$, and its indirect influence via two mediators: actual mobile phone usage and perceived usability of services. To the best of our knowledge, this is the first work to create such a model.

(2) We provide an empirical validation of the model with data from over 600 users.

(3) We give a model of personality traits as a set of facets to increase the generalization power of the results.

(4) We include the disclosure of our Spanish translation of the original personality inventory with higher reliability than prior work [Cupani 2009].

(5) Implications are given for the design of mobile phone services derived from the validated conceptual model.

In the following sections, we explain how the model was developed and empirically validated, and describe our findings and implications for the mobile computing and HCI communities.

\section{FROM PERSONALITY TO CUSTOMER SATISFACTION: A CONCEPTUAL MODEL}

The way people appropriate technology has been previously studied in the literature. Several theoretical models have been introduced and tested to explain user acceptance behavior, such as the theory of reasoned action [Fishbein and Ajzen 1975], the theory of planned behavior [Ajzen 1991], and the technology acceptance model [Davis 1989]. While these models have contributed a great deal to our understanding of users' preferences and acceptance behavior of technological artifacts, they fall short in explaining the users' experience with technology.

User experience encompasses the experiential, affective, and cognitive aspects of a person interacting with a product, system, or service ${ }^{2}$. Therefore it is not limited to the user's intention to use a certain technology. However, user experience models typically do not capture the role of the user's personality when interacting with a certain piece of technology. Ryckman [2004] defined personality as a "dynamic and

\footnotetext{
${ }^{1}$ For simplicity, we refer to mobile phone services evaluated in this study as phone calls, messages (SMS and MMS), and basic GPRS/3G services accessed via prepaid mobile phone numbers.

${ }^{2}$ Adapted from en.wikipedia.org/wiki/User_experience.
} 


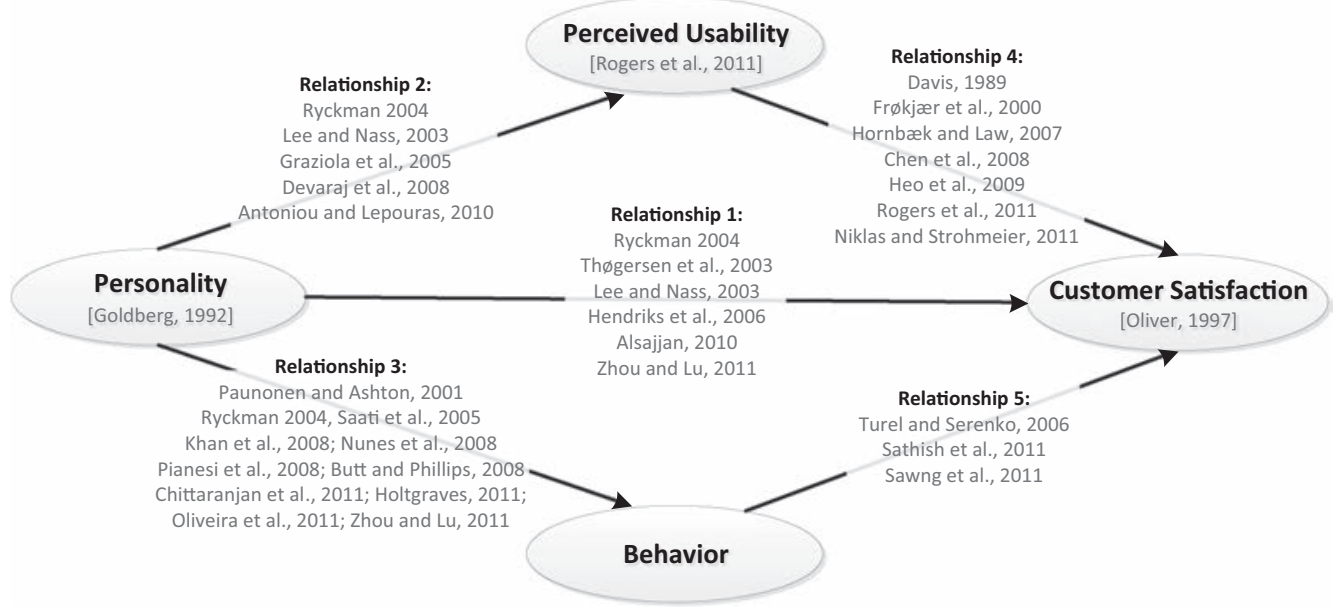

Fig. 1. Proposed conceptual model. References that address each relationship are indicated onto the corresponding arrow or ellipse.

organized set of characteristics possessed by a person that uniquely influences his or her cognitions, motivations, and behaviors in various situations." Recent studies have demonstrated that personality influences directly how people experience the world [Santrock 2008; Paunonen and Ashton 2001]. Moreover, personality psychology has traditionally contributed to social psychology in behavior prediction [Paunonen and Ashton 2001] providing empirical evidence that supports the study of personality to explain differences in human behavior. Hence, we believe that there is an opportunity to better understand the user's interaction with technology by taking into account his/her personality profile.

Personality profiles are typically assessed by means of surveys. Goldberg's [1992] Big Five model is public domain and probably one of today's most well-known, accessible, and empirically validated personality assessment models. It structures a personality profile into five factors (or traits): (1) extroversion (outgoing/energetic versus solitary/reserved); (2) agreeableness (warm/compassionate versus cold/unkind); (3) conscientiousness (efficient/organized versus easy-going/careless); (4) emotional stability (secure/confident versus sensitive/nervous); and (5) intellect (imaginative/curious versus consistent/cautious). Alternative five-factor models have been proposed, such as the NEO-PI-R [Costa and McCrae 1992] (the first four factors are almost identical while the latter-openness versus intellect-is slightly different). The five-factor models of personality are not only well-known in personality psychology, but they are also extensively used by the HCI community [Lee and Nass 2003; Eckschlager et al. 2005; Nunes et al. 2008].

In our proposed model we study the relationship between user personality traits and his/her satisfaction-an important measure of user experience-with mobile services. Moreover, we consider the perceived usability of mobile services and their usage as mediators of the user's experience. Figure 1 depicts our conceptual model and the references related to each of its five conceptual relationships. Note that customer satisfaction was modeled as a separate factor from usability rather than being part of it, as suggested by classical references in HCI [Nielsen 1993]. That said, next we first clarify our reasons for splitting usability from satisfaction, and then we present previous work related to the five conceptual relationships present in the model, followed by our main research questions. 


\subsection{Usability versus Satisfaction}

For many years, user satisfaction with interactive products was largely recognized as part of usability, a key concept in HCI [Nielsen 1993]. Conversely, the proposed model depicted in Figure 1 separates satisfaction from usability for two reasons, one conceptual and the other experimental.

First, the concept of usability has evolved in the past decade, moving towards user experience. As pointed out by Rogers et al. [2011, page 18], the HCI community was once concerned primarily with usability, but has since become concerned with understanding, designing for, and evaluating a wider range of user experience aspects. Therefore, interactive systems should now be designed on the basis of their objectives classified in terms of usability goals and user experience goals. Traditionally-and according to Rogers et al. [2011, pages 19-23], usability goals are related to specific usability engineering criteria (i.e., effectiveness, efficiency, safety, utility, learnability, and memorability), whereas user experience goals aim to explain the nature of the user experience (e.g., interactions more satisfying, enjoyable, engaging, etc.). The authors also point out that the distinction between the two types of goals is not clear-cut, but understanding their differences is useful to clarify their roles.

The second reason for separating satisfaction from usability in our conceptual model came from the data-driven experiments that we carried out to validate the model (see Section 3.4). Before the model parameters were estimated, we conducted a number of validation tests, including convergent and discriminant validity tests. Convergent validity measures internal consistency within any given factor (e.g., if it makes sense to merge efficiency, utility, and ease of use in one factor called usability), whereas discriminant validity verifies whether any given factor is significantly different than the others to justify its existence (e.g., if it makes sense to have one factor for usability and another factor for satisfaction rather than one factor that merges both). Given that the validity tests corroborated our proposed model, we obtained additional evidence supporting the separation between usability and satisfaction, at least for the context considered herein. Nevertheless, and in accordance with Rogers et al. [2011], we would like to stress the importance of understanding the differences between usability and user experience goals, but always considering them together when designing for a specific user experience.

Next we describe the most relevant previous work related to the five conceptual relationships captured in the proposed model (depicted in Figure 1), followed by our research questions.

\subsection{Relationship 1: Personality Traits including Extroversion, Agreeableness, Intellect, Emotional Stability, and Conscientiousness Influence Customer Satisfaction with Mobile Phone Services}

Personality traits influence the way people experience technology. Thøgersen et al. [2003] conducted a study on how personality traits relate to the attitude that consumers have towards complaining about defects of a purchased good and found that complaining depends on the person's attitude towards protesting and on personality traits (negative affectivity). A small association between patients' personality and satisfaction at the end of the care process was also found by Hendriks et al. [2006]. Although these studies did not focus on new technology or mobile services, they do support the idea that personality is linked to the way people experience a certain service.

Personality was also studied with respect to technology acceptance. Lee and Nass [2003] studied the effect of the users' personality traits with their perception of the social presence of a synthetic voice. They found that users had a stronger feeling of social presence when the synthetic voice manifested a personality similar to their own. 
A study that is closer to our work is that of Alsajjan [2010]. He studied how personality traits influence the trust that customers have in their cellular providers. Of the five personality factors, conscientiousness and neuroticism (opposite of emotional stability) had a significant effect on integrity, a dimension of trust often employed to understand the experience of a service. Conversely, Zhou and Lu [2011] observed that, with the exception of conscientiousness, all personality traits have a significant effect on the users' trust in their favorite mobile service.

As can be noticed, small differences in the concept under evaluation (i.e., trust in cellular provider versus trust in favorite mobile service) can greatly impact the influencing role of personality. That said, the proposed model should not necessarily yield results similar to those observed by Alsajjan [2010] or Zhou and Lu [2011] as our target concept is customer satisfaction rather than user trust. Given that our work is one of the first to investigate the influence of customers' personality on their satisfaction with mobile phone services, we believe that all five personality traits could have an important role on influencing customer satisfaction.

\subsection{Relationship 2: Personality Traits including Extroversion, Agreeableness, Intellect, Emotional Stability, and Conscientiousness Influence the Perception of Usability of Mobile Phone Services}

Many researchers have worked on the relation between personality and the measures that are usually taken into account to define the usability of a system. For instance, ease of use and usefulness were studied by Devaraj et al. [2008], who conducted a study with 180 new users of a collaborative technology and found a correlation between the personality dimensions and the perceived usefulness and ease of use. Other related measures of usability have been studied for mobile services. Antoniou and Lepouras [2010] worked on an adaptive mobile museum guide and showed that personality traits are related to the acceptance of the adaptivity dimensions of the service. A similar study was conducted by Graziola et al. [2005], who found a relation between personality traits and the user's preferences of interface modality.

The second relationship in our model differs from the cited previous work as it relates to how personality traits influence customers' perceived usability of the mobile phone services they use. Given that in the study we consider efficiency, ease of use, and utility as the main usability goals that compose the perceived usability factor (see Section 3.1.3), we expect that personality traits related to these attributes could significantly influence the user's perception of usability. For example, people with higher scores for the conscientiousness trait like to do things in a very efficient way [Goldberg 1992]. Hence, if the basic mobile services considered in our study are usually perceived to save people's time, it is expected that people who care about efficiency-higher scores in conscientiousness-will give more importance to this usability goal rather than those who do not care about efficiency at all-lower scores in conscientiousness. Similarly, if these services are indeed useful to contact a variety of people, extroverted users could express their appreciation for these services' utility more than introverted users would. Finally, if these mobile services are not trivial to use, then the intellect trait could also have a significant impact on perceived usability.

\subsection{Relationship 3: Personality Traits including Extroversion, Agreeableness, Intellect, Emotional Stability, and Conscientiousness Influence Mobile Phone Usage}

Personality traits have been shown to influence the way people use technology. The majority of previous work has focused on nonmobile settings. Personality traits have been found useful to predict behavior in the context of keyboard usage [Khan et al. 2008] and recommender systems [Nunes et al. 2008]. In addition, the patterns in the way people use technology have been used to predict personality traits [Saati et al. 
2005; Pianesi et al. 2008; de Oliveira et al. 2011]. Particularly related to our work is the research of Butt and Phillips [2008] who studied the relationship between (selfreported) mobile phone use and personality traits. According to their results, people that scored high in extroversion reported spending more time calling and messaging while people that scored high in neuroticism, disagreeableness, and low in conscientiousness spent more time communicating via SMS. Holtgraves [2011] studied how the personality of a mobile phone user could be inferred by looking at the content of the SMS messages sent by that user. He found significant correlations between certain linguistic categories and extroversion, neuroticism, and agreeableness. Finally, Zhou and $\mathrm{Lu}$ [2011] have recently validated a conceptual model that predicts the influence of personality on behavior intent to adopt mobile commerce services. They found that personality traits do have an influence on the self-reported intention to adopt mobile commerce services.

The third relationship in our model extends Zhou and Lu's [2011] work by studying how personality affects actual behavior-as extracted from mobile call data-rather than intended behavior. In this sense, we employ objective behavior measurements that do not suffer the limitations of self-reported data. Chittaranjan et al. [2011] also used logged mobile phone data and reported significant correlations between extroversion and mobile phone usage. We therefore expect to obtain similar results for the extroversion trait. Note that our work differs from theirs in that we focus on validating the proposed theoretical model (including five relationships) and employ a different methodology of analysis. These differences are explained in more detail in Section 3.6.3.

\subsection{Relationship 4: Perceived Usability Goals (efficiency, ease of use, and utility) Influence Customer Satisfaction with Mobile Phone Services}

Usability goals (i.e., efficiency, effectiveness, safety, utility, learnability, memorability) are commonly positively correlated with how people evaluate their user experience with technology (e.g., satisfying, enjoyable, engaging, etc.) [Rogers et al. 2011]. However, these correlations depend in a complex way on the application domain, the user's experience, and the context of use [Frøkjær et al. 2000]. Additionally, effectiveness, efficiency, and satisfaction should be considered to be different goals [Hornbæk and Lai-Chong Law 2007]. These findings motivate the study of the fourth conceptual relationship in our model, particularly for the domain of mobile services. In this regard, Heo et al. [2009] created a framework to evaluate the usability of mobile services, and showed that there were correlations between usability and user experience constructs, such as satisfaction. In addition, the technology acceptance model has recently been adapted to mobile services by Chen et al. [2008] and Niklas and Strohmeier [2011], and they also found significant correlations between usability metrics and user satisfaction.

Given the extensive HCI literature on the relationship between usability and user experience, we expect a positive impact of perceived usability goals on customer satisfaction with mobile phone services.

\subsection{Relationship 5: Mobile Phone Usage (number of text messages sent/received, number of calls made/received, and duration of calls) Influences Customer Satisfaction with Mobile Phone Services}

Finally, the way customers use mobile technology influences their experience of the mobile services they use. Turel and Serenko [2006] worked on a model that incorporated self-reported behavioral accounts of mobile service usage. They found that it was possible to use these measures to benchmark service operators in terms of customer satisfaction, and loyalty. Similarly, Sawng et al. [2011] worked on a model that included social benefits, satisfaction, and service risks and that could be used to predict customer behavior when using mobile phone services. In market research, behavioral patterns are 
typically used to predict the probability that a customer will switch to a different operator (i.e., churn). For instance, Sathish et al. [2011] studied the factors that affect churn decisions in India. They found that self-reported call frequency was among the most important factors in determining whether customers were satisfied with their carriers.

The fifth relationship in our model studies the impact that actual-as recorded by the operator-mobile phone usage has on customer satisfaction with mobile services. Particularly, we believe that overusing mobile services has a number of side-effects that could reduce customer satisfaction, including mental and physical stress, more expensive monthly phone bills, and greater exposure to failures in the services. We therefore expect this conceptual relationship to be significant and negative.

\subsection{Research Questions}

The main goal of this work is to shed light on the impact that personality traits have on the user's experience-as characterized by satisfaction-of mobile services. To the best of our knowledge, the closest work to ours is that of Zhou and $\mathrm{Lu}$ [2011]. However, our approach differs in three fundamental ways: (1) We focus on objective behavior and not self-reported accounts of how often customers use mobile services; (2) we probe customers' actual experience with mobile services rather than their intention to use these services; and (3) our estimation method quantifies the relationships among concepts whereas the method used by those authors aims at fine-tuning variables to predict the value of another variable.

Hence, the main research questions addressed in this article include the following.

$R Q 1$. Can the proposed conceptual model be empirically validated?

RQ2. How (if at all) will the proposed conceptual model help us understand the influence that personality traits have on customer satisfaction with mobile phone services?

Next we describe our experimental design in order to answer these questions.

\section{USER STUDY}

We deployed a user study in order to empirically validate the conceptual model depicted in Figure 1. Our method combines collected mobile network usage data with survey data. A similar approach was suggested by Verkasalo [2009], although he proposed to use mobile phone usage metrics collected at the handset level which required a specific software to be installed on the phone. Our approach does not require extra manipulation of the participants' devices and allows feature phone users to take part in the study as well. In this section, we present details of the study methodology and major findings.

\subsection{Procedure}

3.1.1. Sampling. Participants were recruited via email from an online panel with members living in Mexico and who satisfied two filtering criteria: (1) their age was between 18 and 35 years old, and (2) they all owned a prepaid mobile phone number from the same mobile operator for at least the period between January to June 2010. While the first requirement guaranteed our study would yield significant results for the youth and adult segments (personality traits can significantly vary with age [Goldberg et al. 1998]), the latter ensured the availability of enough mobile phone usage data retrieved from the participants' Call Detail Records (CDRs).

3.1.2. Data Gathering. Participants' mobile phone usage was objectively measured via Call Detail Records. CDRs are generated when a mobile phone connected to the network makes or receives a phone call or uses a service (SMS, MMS, etc.). In the process, the 
information regarding the connection is stored in the form of a CDR, which includes the originating and destination phone numbers, the time and date of the call, the total length of the call, and the cell tower used for the communication. All originating and destination numbers were encrypted to preserve privacy and all participants had given their written consent to give access to their anonymized CDRs for the purposes of this study.

Participants were asked to fill out an online survey with two main sections.

(1) Personality section. Participants filled out a public-domain Big Five personality assessment questionnaire available on the IPIP Web site to easy access and replication of our findings. Historically, the IPIP Big Five measures were constructed by identifying items that correlate highly with Goldberg's [1992] lexical scales. The 50 -item version ${ }^{3}$ was chosen due to its good balance between low number of questions and high level of internal consistency (Cronbach's alpha: .79 to .87). Reverse translation was applied to this questionnaire targeting a Mexican Spanish translation. Later on, our translated inventory was compared against Cupani's [2009] Argentinean Spanish version: whenever our items were similar to his version, we maintained his validated translation. Our translated items were kept when we found divergences that seemed to be due to cultural differences between the two Spanish-speaking countries;

(2) Opinion section. The questionnaire also included two sets of questions to collect the participants' opinion about the mobile phone services that they were using (i.e., calls, SMS, MMS, and basic GPRS/3G-related services). While the former set of questions assessed HCI usability goals usually considered for the context of basic mobile phone services (i.e., ease of use, efficiency, and utility), the latter contained customer satisfaction questions similar to those used by Turel and Serenko [2006] and typically used in studies of market research for telecommunication companies (i.e., general satisfaction with paid mobile phone services, expectations versus reality, and comparison with ideal mobile phone services).

3.1.3. Measuring Usability. For many years, usability goals like the ones considered in our study (i.e., ease of use, efficiency, utility) have been measured in controlled settings. However, Rogers et al. [2011] point out that usability testing has been increasingly performed remotely or in natural settings. In fact, Nielsen and Levy's [1994] work on the relationship between self-reported measures and objective measures of usability have encouraged the community to also consider measuring usability in a subjective manner. We opted for measuring usability using a questionnaire mainly due to three reasons.

First, and according to Rogers et al. [2011], a typical usability test conducted in a controlled setting would not only significantly reduce ecological validity, but also the number of participants and hence statistical power of our findings as required by the validation methodology (see Section 3.4).

Second, we primed respondents to think about their use of three mobile services: (1) phone communications, (2) short messaging, and (3) GPRS/3G data connections. Given that participants were mostly feature phone users (93\%) using these hardwareindependent services that were equally accessible to all participants, we argue that the overall measured usability was therefore related to the services themselves, and not to a mix of different hardware and software products with different performances.

And third, our recruitment criteria guaranteed that all participants performed tasks related to these mobile services for at least six months. In the case of phone communication, the related tasks include establishing a communication with a peer and exchanging communicative content (similar tasks were conducted for the other

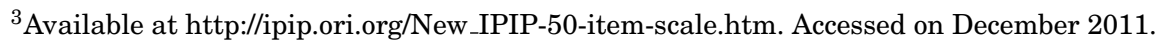


services). This means that all participants performed-in their natural environmenttasks related to all mobile services considered in our study for a significant period of time before subjectively evaluating their usability.

3.1.4. Pilot. We deployed a pilot with 39 participants to test the experimental material before going large scale. After a successful pilot, we were ready to deploy the study. Note that all the findings presented in this article are based on the data collected in the final study exclusively (postpilot).

\subsection{Participants}

A total of 603 valid responses (male: $50.2 \%$, controlled for a balanced distribution) were obtained in the final study. The participants' age ranged between 18 and 35 years old $(\bar{x}=25.87, s=5.25)$-as per our invitation filtering criteria-and they predominantly belonged to the middle socio-economic class. With respect to their professional activity, $42.1 \%$ were employed, $23.7 \%$ were students, $19.9 \%$ were self-employed, $6.1 \%$ were unemployed, and $8.2 \%$ were in a different job situation (e.g., retired, housewife, etc.). Participants were familiar with technology: the majority reported using computers $(93.4 \%)$ and the Internet $(92.4 \%)$ at least once a week. In terms of mobile phone use, $81.6 \%$ reported using their mobile phone everyday, $14.8 \%$ several times a week, $2.7 \%$ only once a week, and $0.9 \%$ less than once a week. On the basis of their actual mobile phone call data (CDRs), participants made or received an average of 101 calls per month and sent or received 171 messages per month.

\subsection{Measures}

Items were measured either subjectively or objectively. A total of seven constructs were created from survey items and hence subjectively measured: extroversion, agreeableness, conscientiousness, emotional stability, intellect, perceived usability, and satisfaction with mobile phone services. Each of the five personality traits were captured by 10 survey items (50 items in total) that were later grouped into personality facets using Goldberg [1999]'s classification as shown in Table I. This was performed by computing summated scales for each facet, that is, summating all positive survey items and reversed negative items related to the same facet. For instance, if one participant gave the ratings 2,8 , and 7 to the survey items $q 8 r, q 33$, and $q 43$, respectively (see Table I), then the summated scale for his/her orderliness personality facet would be: $(10-2)+8+7=23$. The remaining two subjectively measured factors-perceived usability and customer satisfaction-were assessed using their corresponding survey items from Table I, which were related to the mobile services contracted by the participants (phone calls, SMS/MMS, and basic GPRS/3G services). Finally, mobile phone usage was the only factor composed of items that were measured objectively: the total number of mobile phone calls made/received between January and June 2010, the total duration of phone calls, and the total number of messages sent/received during the same period. Table I summarizes all data and constructs used in the study.

\subsection{Statistical Analysis}

The conceptual model depicted in Figure 1 (note that we expanded the personality variable into the Big Five traits) was evaluated using Structural Equation Modeling (SEM) [Blunch 2008]. We highlight at least three reasons for using this approach.

(1) SEM models relationships between concepts given that its objective function maximizes the probability of predicting the covariance matrix instead of predicting values of a certain variable. 
Table I. Construct Factors and Associated Items Captured Subjectively by the Survey and Objectively by the Mobile Phone Operator

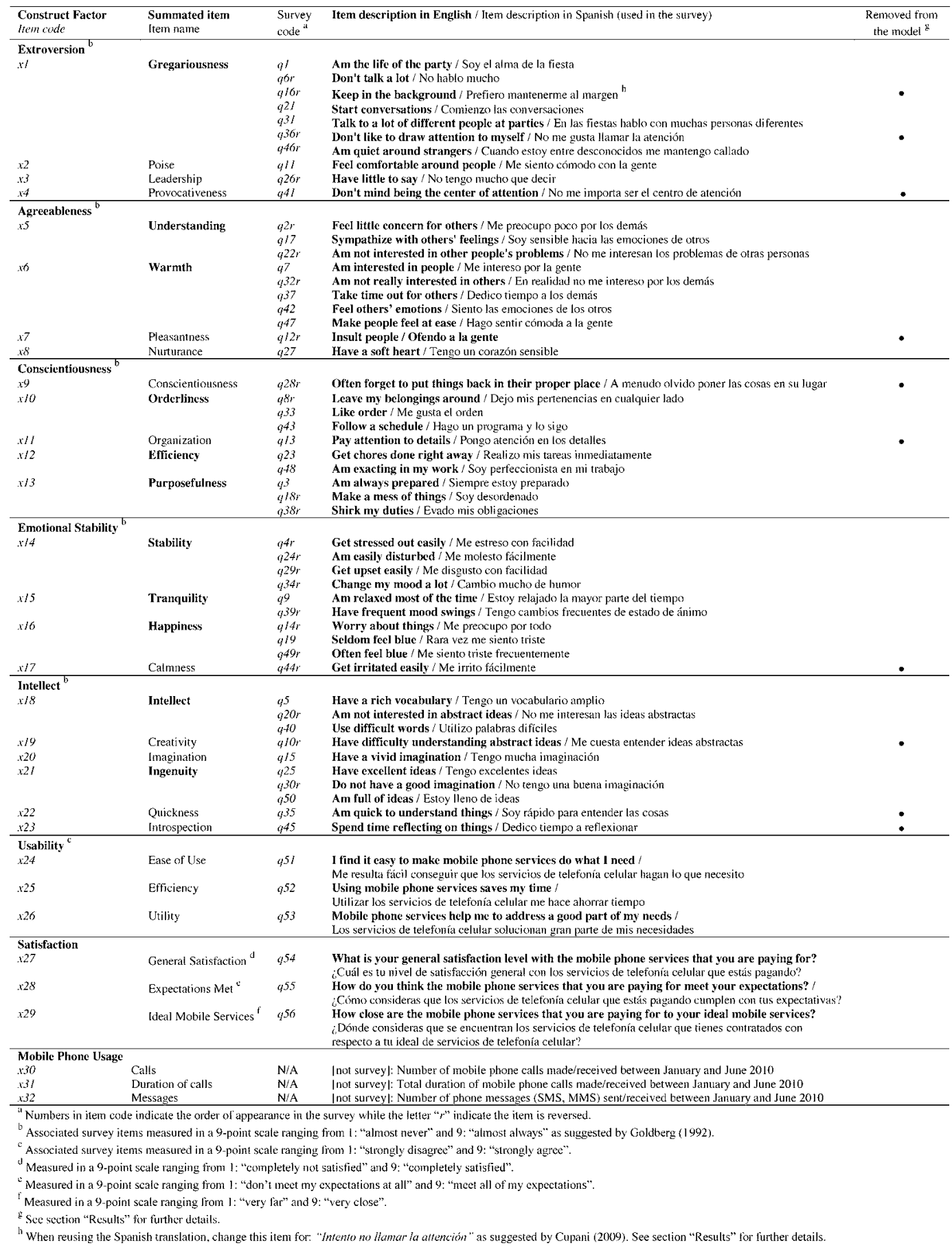

ACM Transactions on Computer-Human Interaction, Vol. 20, No. 2, Article 10, Publication date: May 2013. 
(2) SEM takes measurement unreliability into account by modeling equation errors and nonmeasurable concepts-for example, extroversion, satisfaction-as latent variables, thus avoiding unrealistic assumptions of error-free measurements.

(3) SEM allows researchers to leverage previous knowledge given that it uses confirmatory rather than exploratory factor analysis, which fits the purpose of validating a conceptual model.

Estimation and evaluation. In SEM, the model parameters are estimated by minimizing a function $f$ of the difference between the actual covariance matrix representing the relationship between variables and the estimated covariance matrix of the best fitting model, as

$$
F=f\left(S-\sum(\theta)\right)
$$

where $S$ is the empirical covariance matrix and $\sum(\theta)$ is the covariance matrix implied by a model with the parameters $\theta$. For the fit function $F$, we used Maximum Likelihood (ML), the standard and preferred estimation method for covariance-based SEM [Olsson et al. 2000]. This method estimates parameters as the values that have the largest probability of producing the sample covariance matrix $S$. ML estimation assumes multivariate normality of indicators (i.e., items in the questionnaire). However, items measuring mobile phone usage revealed severe nonnormality and hence were logarithmically transformed to reduce critical ratios of skewness and kurtosis towards approximating near-normal distributions. We further bootstrapped the data $(1,000$ samples) to meet the ML's assumption of joint multivariate normality of observed variables [Blunch 2008]. This procedure is also highly recommended for testing indirect effects among constructs [MacKinnon et al. 2002], which was performed in order to understand the total effect of personality traits on customer satisfaction.

The SEM estimation process was split in two steps [Anderson and Gerbing 1988]: First we developed a measurement model (i.e., relationship between each factor construct—e.g., extroversion-and its corresponding items-e.g., gregariousness, poise, leadership, and provocativeness) before actually estimating the regression weights in the structural model (i.e., relationships between factor constructs-e.g., influence of extroversion on customer satisfaction). In other words, each item was restricted to load on its a priori factor, and the factors themselves were allowed to correlate. The measurement model was then evaluated for unidimensionality, reliability, convergent, and discriminant validity. Finally, the hypothesized structural paths between constructs were included in the model for the final estimation. Given that the usual $\chi^{2}$-test is sensitive to sample size [Blunch 2008], we opted for the most common strategy of evaluating model fit using indices, such as Standardized Root Mean Squared Residual (SRMR < .08), Root Mean Squared Error of Approximation (RMSEA < .06), Comparative Fit Index $(\mathrm{CFI}>.95)$, and Parsimony Ratio (PRATIO > .60) [Hu and Bentler 1999; Blunch 2008].

Cross-validation. The sample was randomly split in two halves-as recommended by Schumacker and Lomax [2004] -and cross-group equivalence was performed to test fit for both halves using the same conceptual model (first the measurement model and then the structural model, as recommended by Blunch [2008]). This procedure involves a number of tests where parameters are constrained-step by step-to the same value across groups, as the following five questions are asked.

(1) Configural invariance. Is the model structure the same across groups? In this step, groups were constrained to the same structural and measurement models, but all parameters were free to vary. 
(2) Metric invariance. Are the regression weights equal across groups? In this second step, the previous model was further constrained to the same regression weights in both measurement and structural models.

(3) Factor covariance invariance. Are the factors interrelated in the same way across groups? In this third step, the previous model was restricted to have the same factor covariances across groups (i.e., between each pair of personality trait).

(4) Factor variance invariance. Do the factors exhibit the same variation across groups? In this fourth step, every factor in the previous model was constrained to the same variance across groups.

(5) Error variance/covariance invariance. Are the error variances and covariances equal across groups? In this last step, we reused the previous model and constrained variances and covariances of all error variables to the same value across groups.

Finally, the proposed conceptual model was considered valid only if each of the increasingly constrained models could fit the data without significantly degrading fit indices from one less constrained model to the following more constrained model-as indicated by nonsignificant changes in $\chi^{2}(p>.05)$ or in CFI $(\Delta \mathrm{CFI}>-.01)$ [Cheung and Rensvold 2002].

The procedure described before was also used to verify whether gender and amount of mobile phone usage data considered per user (e.g., 6-month versus 1-month data) have an impact on the proposed model.

\subsection{Results}

In this section we summarize the reliability results of our personality questionnaire, followed by the validation of the measurement model and the structural model towards addressing our first research question. Cross-validation results are reported last.

3.5.1. Reliability of the Translated Personality Inventory. As explained before, our Mexican Spanish version of the 50-item IPIP personality questionnaire was derived from Cupani's [2009] Argentinean Spanish version. While Cupani reports Cronbach's alpha ranging from .70 and .78, our adaptation achieved better results: .73 (extroversion), .77 (agreeableness), .83 (conscientiousness), .81 (emotional stability), and .80 (intellect). This indicates that our personality inventory has good reliability, which reinforces the foundations of our conceptual model.

3.5.2. Measurement Model. Item analysis suggested that most personality facets measured by only one survey item (e.g., $x 4$ : provocativeness) were violating the unidimensionality assumption of their corresponding construct factors and should therefore be removed. Reliability and convergent validity analyses yielded similar results. This finding is somewhat expected given that one survey item provides limited information about one personality facet. That said, facets composed of one survey item were removed until each personality trait-construct factor-would be characterized by at least three facets (minimum number of indicators recommended per construct [Blunch 2008]). The best candidates for removal were identified by means of reliability and unidimensionality analyses. Consequently, the following 1-item facets were removed from the measurement model: $x 4$ (provocativeness), $x 7$ (pleasantness), $x 9$ (conscientiousness), $x 11$ (organization), $x 17$ (calmness), $x 19$ (creativity), $x 22$ (quickness), and $x 23$ (introspection). This step not only improved the reliability and validity of the constructs, but also increased the model's parsimony and representativeness of each personality trait (all construct factors now would equally load on three facets).

Convergent validity analysis pointed out that the extroversion factor should be further improved (composite reliability $=.69$ ). In fact, a couple of the items used to compute the gregariousness summated scale had low item-total correlations: $q 16 r$ ("Keep 
Table II. Reliability and Convergent Validity Results

\begin{tabular}{|c|c|c|c|c|c|c|}
\hline Constructs & Items & Loadings & SE & CR & AVE & $\alpha$ \\
\hline \multirow[t]{3}{*}{ F1: Extroversion } & $x 1$ & 0.784 & 0.031 & 0.721 & 0.557 & 0.701 \\
\hline & $x 2$ & 0.742 & 0.031 & & & \\
\hline & $x 3$ & 0.498 & 0.045 & & & \\
\hline \multirow[t]{3}{*}{ F2: Agreeableness } & $x 5$ & 0.517 & 0.040 & 0.729 & 0.600 & 0.728 \\
\hline & $x 6$ & 0.992 & 0.035 & & & \\
\hline & $x 8$ & 0.499 & 0.041 & & & \\
\hline \multirow[t]{3}{*}{ F3: Conscientiousness } & $x 10$ & 0.725 & 0.028 & 0.808 & 0.712 & 0.809 \\
\hline & $x 12$ & 0.797 & 0.027 & & & \\
\hline & $x 13$ & 0.770 & 0.027 & & & \\
\hline \multirow[t]{3}{*}{ F4: Emotional Stability } & $x 14$ & 0.804 & 0.038 & 0.726 & 0.581 & 0.701 \\
\hline & $x 15$ & 0.804 & 0.039 & & & \\
\hline & $x 16$ & 0.411 & 0.048 & & & \\
\hline \multirow[t]{3}{*}{ F5: Intellect } & $x 18$ & 0.518 & 0.037 & 0.723 & 0.559 & 0.708 \\
\hline & $x 20$ & 0.700 & 0.031 & & & \\
\hline & $x 21$ & 0.812 & 0.030 & & & \\
\hline \multirow[t]{3}{*}{ F6: Usability } & $x 24$ & 0.593 & 0.041 & 0.741 & 0.591 & 0.729 \\
\hline & $x 25$ & 0.836 & 0.033 & & & \\
\hline & $x 26$ & 0.657 & 0.040 & & & \\
\hline \multirow[t]{3}{*}{ F7: Satisfaction } & $x 27$ & 0.936 & 0.013 & 0.914 & 0.893 & 0.882 \\
\hline & $x 28$ & 0.861 & 0.017 & & & \\
\hline & $x 29$ & 0.851 & 0.015 & & & \\
\hline \multirow[t]{3}{*}{ F8: Mobile Phone Usage } & $x 30$ & 0.968 & 0.011 & 0.892 & 0.862 & 0.914 \\
\hline & $x 31$ & 0.912 & 0.014 & & & \\
\hline & $x 32$ & 0.669 & 0.027 & & & \\
\hline
\end{tabular}

SE: standard error; CR: composite reliability; AVE: average variance extracted.

All regression loadings are standardized and significant at $p=.001$. See Table I for details on the items.

in the background") and $q 36 r$ ("Don't like to draw attention to myself"), due to a somewhat poor translation and a confusing negative expression, respectively. These survey items were therefore removed from the gregariousness summated scale. Subsequent convergent and discriminant analyses validated the measurement model as indicated by results presented in Tables II and III. Note that all values for Composite Reliability $(\mathrm{CR})$ and Cronbach's alpha $(\alpha)$ exceeded 0.70. Moreover, all values for Average Variance Extracted (AVE) were greater than 0.50 . These results confirm good reliability and convergent validity [Bagozzi and Yi 1988], meaning that constructs are closely related to their corresponding items. Furthermore, Table III shows that the square root of AVE for each factor-in the diagonal-was larger than its correlation coefficients with the other factors, thus confirming a good discriminant validity [Fornell and Larcker 1981]. This means that all pairs of constructs are statistically different and that the model correctly differentiates among them.

3.5.3. Structural Model. Given that our proposed constructs had strong theoretical foundations-as discussed in the "Model" section-and were also empirically supported by the measurement model analysis, we evaluate next the hypothesized structural relationships. Figure 2 depicts the final conceptual model with the most relevant statistics. As expected, chi-square was significant given its sensitivity to sample size $\left(\chi^{2}=621.595, d f=225, p<.01\right)$. Nevertheless, more appropriate fit measures for our case such as SRMR (.049), RMSEA (.054), CFI (.938), and PRATIO (.815) reveal that our model is valid as it has a good fit according to widely accepted cutoff criteria [Hu and Bentler 1999; Blunch 2008]. 
Table III. Discriminant Validity Results

\begin{tabular}{lcccccccc}
\hline & F1 & F2 & F3 & F4 & F5 & F6 & F7 & F8 \\
\hline F1: Extroversion & 0.75 & & & & & & & \\
F2: Agreeableness & 0.58 & 0.77 & & & & & & \\
F3: Conscientiousness & 0.60 & 0.53 & 0.84 & & & & & \\
F4: Emotional Stability & 0.51 & 0.27 & 0.42 & 0.76 & & & & \\
F5: Intellect & 0.63 & 0.53 & 0.61 & 0.34 & 0.75 & & & \\
F6: Usability & 0.47 & 0.36 & 0.46 & 0.23 & 0.39 & 0.77 & & \\
F7: Satisfaction & 0.17 & 0.08 & 0.22 & 0.12 & 0.05 & 0.45 & 0.94 & \\
F8: Mobile Phone Usage & 0.15 & 0.10 & 0.10 & 0.05 & 0.07 & 0.05 & -0.08 & 0.93 \\
\hline
\end{tabular}

Square root of Average Variance Extracted in the diagonal of the matrix, with factor correlation coefficients in the remaining cells.

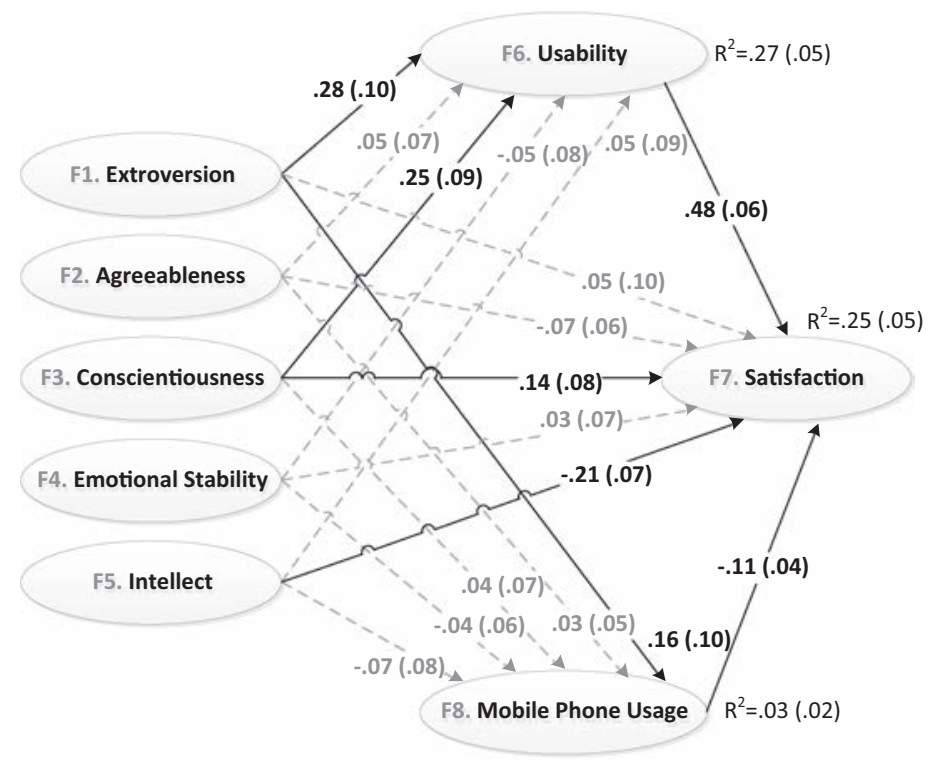

Fig. 2. Validated conceptual model. Standardized loadings next to the corresponding arrows with standard errors in parentheses (bootstrapping to 1000 samples). Significant paths $(p<.05)$ indicated by solid black arrows and nonsignificant paths indicated by grey dashed arrows. Error variables and covariance paths omitted for clarity.

From the statistics presented in Figure 2, one can identify the direct effects between constructs (e.g., $\beta_{71}=.05$ for the direct effect of F1: extroversion on F7: satisfaction), and compute the indirect effects between them (e.g., $\beta_{71}^{\text {indirect }}=\beta_{61} \times \beta_{76}+\beta_{81} \times \beta_{78}=$ $.28 \times .48+.16 \times-.11=.11$ for the indirect effect of F1: extroversion on F7: satisfaction via direct effect on mediators F6: usability and F8: mobile phone usage). Finally, the total effect is calculated by adding both direct and indirect effects (e.g., $\beta_{71}^{\text {total }}=\beta_{71}+$ $\beta_{71}^{\text {indirect }}=.05+.11=.16$ for the total effect of F1: extroversion on F7: satisfaction). Table IV summarizes the standardized direct, indirect, and total effects of personality traits on the participants' satisfaction with mobile phone services.

3.5.4. Cross-Validation. As previously explained, we performed cross-group equivalence of two random halves of the sample. Table $\mathrm{V}$ summarizes the main results. Note that all $\chi^{2} p$-values were not significant after imposing each of the five constraints to models 
Table IV. Standardized Effects of Personality Traits on Satisfaction

\begin{tabular}{lrrr}
\hline & Direct Effect & Indirect Effect & \multicolumn{1}{c}{ Total Effect } \\
\hline Extroversion & $0.047(0.099)$ & $\mathbf{0 . 1 1 3 ( 0 . 0 5 5 )}$ & $\mathbf{0 . 1 6 1 ( 0 . 0 9 6 )}$ \\
Agreeableness & $-0.070(0.061)$ & $0.020(0.034)$ & $-0.049(0.062)$ \\
Conscientiousness & $\mathbf{0 . 1 3 5 ( 0 . 0 8 1 )}$ & $\mathbf{0 . 1 1 6 ( 0 . 0 4 8 )}$ & $\mathbf{0 . 2 5 1 ( 0 . 0 7 8 )}$ \\
Emotional Stability & $0.026(0.065)$ & $-0.019(0.039)$ & $0.007(0.064)$ \\
Intellect & $\mathbf{- 0 . 2 1 1 ( 0 . 0 7 3 )}$ & $0.033(0.046)$ & $-\mathbf{0 . 1 7 8}(\mathbf{0 . 0 7 9})$ \\
\hline
\end{tabular}

Standard errors in parentheses. Significant effects $(p<.05)$ in bold.

Table V. Cross-Validation Results

\begin{tabular}{lcccccc}
\hline Models & $\chi^{2} / d f$ & $\Delta \chi^{2} / d f$ & $p$ & $\Delta$ RMSEA & $\Delta$ PRATIO & $\Delta$ CFI \\
\hline$M_{1}$ : Configural invariance & 1.941 & & & & & \\
$M_{2}$ : Metric invariance & 1.886 & -0.055 & 0.271 & -0.002 & 0.060 & -0.001 \\
$M_{3}$ : Factor covariance invariance & 1.858 & -0.028 & 0.480 & 0 & 0.018 & 0.001 \\
$M_{4}$ : Factor variance invariance & 1.849 & -0.009 & 0.494 & 0 & 0.009 & 0 \\
$M_{5}$ : Error variance/covariance invariance & 1.822 & -0.027 & 0.238 & -0.001 & 0.049 & -0.001 \\
\hline
\end{tabular}

Cross-group equivalence of two random halves taken from the original sample. Delta fit measures are computed by subtracting measures from models $M_{n}$ and $M_{n-1}$.

generated for both halves, thus supporting the generalization power of our proposed conceptual model (see Figure 2).

In addition, we divided the original sample in two groups using gender as the grouping variable. Multigroup analysis validated the model for samples with only men or women $\left(\Delta \mathrm{CFI}_{\max }=-.002\right)$. Therefore, gender does not have an effect on the proposed conceptual model.

We also investigated whether the amount of Call Detail Record data considered per participant could have an effect in the proposed model. We hence performed cross-group equivalence of four copies of the full dataset-containing data from 603 participantsin which we considered participants' 6-month, 3-month, 2-month, and 1-month mobile phone usage data, respectively. Results reveal that the amount of CDR data used in the analysis does not have a significant ${ }^{4}$ impact in the proposed model $\left(\Delta \mathrm{CFI}_{\max }=.001\right)$.

The results presented in this section corroborate our first research question by proving that the proposed conceptual model can be empirically validated.

\subsection{Discussion}

In this section we address our second research question by discussing each of the five conceptual relationships of the validated model to shed light on how personality can influence customer satisfaction with mobile phone services.

3.6.1. Perceived Usability Goals (Efficiency, Ease of Use, and Utility) Influence Customer Satisfaction with Mobile Phone Services (Relationship 4). Indeed the usability of mobile phone services was positively correlated with the customers' satisfaction with these services $\left(\beta_{76}=.48, p=.002\right)$. The standardized direct effect of usability on satisfaction was .48, which means that when usability goes up by 1 standard deviation, satisfaction goes up by .48 standard deviation, and hence has a very strong influence on it. This is in accordance with prior literature in which the usability goals considered herein were also

\footnotetext{
${ }^{4}$ This result does not reveal that the model with 1-month data is as accurate as the model with 6-months data, but rather that their residual matrices $S-\sum(\theta)$ do not significantly differ judged by various fit functions (e.g., RMSEA, CFI). In other words, one may find little differences in some regression weights by using 1-month or 6-month data (e.g., the impact of extroversion on mobile phone usage is clearer with 6-month data than with 1-month data), but both datasets would fit in the same conceptual model with all parameters $\theta$ constrained to the same values across datasets.
} 
shown to have a significant effect on customer satisfaction with mobile phone services [Chen et al. 2008; Heo et al. 2009; Niklas and Strohmeier 2011; Sawng et al. 2011]. With respect to the key usability goals that defined customer satisfaction in our model, service efficiency came in first place $\left(R^{2}=.70\right)$, followed by its utility $\left(R^{2}=.43\right)$ and ease of use $\left(R^{2}=.35\right)$. From a pairwise analysis, the only significant differences were between efficiency and utility $\left(\Delta \chi^{2} / d f=11.278, p=.001\right)$, and between efficiency and ease of use $\left(\Delta \chi^{2} / d f=20.512, p<.001\right)$. However, the model did not change significantly when usability loadings for utility and ease of use were constrained to be equal $\left(\Delta \chi^{2} / d f=1.351, p=.245\right)$. These results indicate that customers of basic mobile phone services tend to appreciate more these services' efficiency rather than their utility and ease of use.

3.6.2. Mobile Phone Usage (Number of Messages Sent/Received, Number of Calls Made/ Received, and Duration of Calls) Influences Customer Satisfaction with Mobile Phone Services (Relationship 5). According to our model, this influence is rather negative $\left(\beta_{78}=-.11, p=\right.$ .002 ), meaning that the more one uses mobile phone services, the less satisfied one would be with them. We identify two potential explanations of this finding.

The first one is based on unexpected high expenses: the more people use their mobile phones, the more they will have to pay for them (note that our sample included only customers of prepaid phones and hence did not have a flat phone plan). While some tend to be organized and plan their lives so to avoid unpleasant surprises in terms of mobile phone costs, others are not. In the latter case, a large number of phone calls could be a threat to their satisfaction with mobile services because of high unexpected phone bills or fast consumption of their prepaid balance. Future work shall address this point by investigating the impact of the customers' sensitiveness to price on their satisfaction.

The second explanation is based on the observation that technology consumption seems to have a saturation point. Satisfaction can be maintained up to a point where the given technology addresses people's needs without compromising their daily routines and personal values. If by overusing mobile phone services one jeopardizes these routines and values, then dissatisfaction might be a natural outcome due to several reasons, for example, realizing that too much time is being wasted using them, creating anxiety to keep up with the flow of messages and calls, etc. Note that the construct factor for mobile phone usage comprised more information about synchronous disruptive activities like phone calls $\left(R^{2}=.94\right)$ and their durations $\left(R^{2}=.83\right)$ than about sent/received asynchronous text messages $\left(R^{2}=.45\right)$. Therefore, the mobile phone usage patterns as captured by our model include mostly activities that can break daily routines and hence be more susceptible to the argument of technology consumption saturation point.

Previous work demonstrated the existence of a link between self-reported usage behavior and satisfaction with mobile services [Turel and Serenko 2006; Sawng et al. 2011; Sathish et al. 2011]. Also Waber et al. [2008] in a real-world mobile sensing experiment found that an increasing amount of face-to-face interaction in the workplace was negatively correlated with perceived group interaction quality. Our work goes one step further by quantifying the negative relationship, suggesting possible explanations, and considering actual mobile phone usage.

3.6.3. Personality Traits Including Extroversion, Agreeableness, Intellect, Emotional Stability, and Conscientiousness Influence Mobile Phone Usage (Relationship 3). The only personality trait that was found to have a significant influence on mobile phone usage was extroversion $\left(\beta_{81}=.16, p=.045\right.$ one-tailed test as recommended by Blunch [2008, page 100], $\beta_{81}^{\text {low }}=.01, \beta_{81}^{u p}=.32,90 \%$ percentile-corrected confidence interval). That is, the higher one scores on the extroversion trait, the more one uses the mobile phone-either for 
sending or receiving calls/SMS. This finding may seem obvious, given that by definition extroverts do approach people more often than introverts. In fact, Butt and Phillips [2008] observed significant correlations between people's extroversion level and mobile phone usage (between $r=.13$ and $r=.28$ ). However, their findings were based on self-reported mobile phone usage data whereas our work confirms their findings using actual mobile data. Note that Chittaranjan et al. [2011] also used logged mobile phone data and reported significant correlations between extroversion and mobile phone usage (between $r=-.13$ and $r=.20$ ). Our findings corroborate these results and further expand these authors' work. First, our sample is about one order of magnitude higher, thus guaranteeing a larger statistical power for generalization purposes. Second, we employed a multivariate data analysis methodology that does not isolate the effect between pairs of variables, but rather takes into account the complex relationship among different variables and the unreliability of their measurements. Finally, our model reveals both the influence of personality traits on mobile phone usage and which personality facets determine the given influence. More specifically, we verified that gregariousness $\left(R^{2}=.62\right)$ and poise $\left(R^{2}=.55\right)$ - as opposed to leadership $\left(R^{2}=.25\right)$ were the main facets contributing to the positive effect of extroversion on mobile phone usage. Leadership's lower relevance was indicated by the significant difference with gregariousness $\left(\Delta \chi^{2} / d f=44.056, p<.001\right)$ and poise $\left(\Delta \chi^{2} / d f=22.551, p<.001\right)$, whereas gregariousness and poise were considered equally important as no significant difference was found between them $\left(\Delta \chi^{2} / d f=1.918, p=.166\right)$.

3.6.4. Personality Traits Including Extroversion, Agreeableness, Intellect, Emotional Stability, and Conscientiousness Influence the Perception of Usability of Mobile Phone Services (Relationship 2). Extroversion $\left(\beta_{61}=.28, p=.004\right)$ and conscientiousness $\left(\beta_{63}=.25, p=.005\right)$ had significant effects on perceived usability of mobile phone services. The interpretation of this finding is grounded on behavior theories associated to personality traits. If today's mobile phone services provide the right kind of functionality so that users can shorten distances between people and allow them to interact more often, it is expected that extroverts-who interact with peers more frequently-will consider these services to have good utility and hence highly evaluate their usability. Likewise, if these services indeed help people save time, one would expect that those who care about efficiency when following daily schedules - that is, people with high scores on the conscientiousness trait-would positively rate the services' usability. One the other hand, the intellect trait does not seem to influence the user's perception of usability $\left(\beta_{65}=.05, p=.55\right)$. We originally expected that this relationship could exist if people's opinion about the easiness to use mobile phone services would diverge. In that case, people with low scores on the intellect trait could find these services harder to use than people with high scores on the same trait. However, the previous finding suggests that one's intellect trait is not related to how one perceives the easiness to use basic mobile services.

We cannot directly compare our work with previous models because these studies do not group usability goals into one single factor [Sawng et al. 2011; Zhou and $\mathrm{Lu}$ 2011]. However, our work offers synergic findings by revealing that extroversion and conscientiousness have a significant effect on the usability construct (composed of efficiency, utility, and ease of use).

3.6.5. Personality Traits Including Extroversion, Agreeableness, Intellect, Emotional Stability, and Conscientiousness Influence Customer Satisfaction with Mobile Phone Services (Relationship 1). According to Figure 2, only conscientiousness and intellect have a significant direct impact on customer satisfaction: conscientiousness with a positive influence $\left(\beta_{73}=\right.$ $.14, p=.04$ one-tailed test, $\beta_{73}^{\text {low }}=.01, \beta_{73}^{u p}=.27,90 \%$ percentile-corrected confidence level) and intellect with a negative one $\left(\beta_{75}=-.21, p=.002\right)$. Note that this is only 
due to the direct effect of these variables on satisfaction. However, the indirect effect through usability and mobile phone usage should also be taken into account. For example, according to Table IV the standardized total effect of conscientiousness on satisfaction is $.25(p=.003)$ rather than .14 . This corresponds to a $79 \%$ increase with respect to the direct effect due to indirect influences of that personality trait via mediators F6 (perceived usability) and F8 (mobile phone usage). Therefore, we conclude that people with high scores on the conscientiousness trait do not only tend to positively evaluate the usability of mobile phone services, but they are also more satisfied with them. This result is in accordance with the finding by Alsajjan [2010]. Although this could be seen as a straightforward conclusion, note that good usability is not sufficient to guarantee customer satisfaction. For example, one could imagine services with poor customer support that diminish satisfaction regardless of good usability. We plan on evaluating this effect in future work.

With respect to the influence of intellect on satisfaction, its standardized total effect was $-.18(p=.02)$ and hence slightly less relevant (but still significant) than its direct effect $(-.21)$. These results indicate that the higher one's self-reported scores on the intellect trait, the lower one's satisfaction with mobile phone services. Interestingly, Vigoda-Gadot and Meisler [2010] verified the opposite conclusion when evaluating job satisfaction in the public sector. According to their study, employees with high levels of emotional intelligence are more dedicated and satisfied at work. It is important to note, however, that our research focuses on the satisfaction of customers with mobile phone services instead of work conditions. While in the former case subjects pay for a set of services, in the latter they get paid for offering a different set of services. Such reversed logic probably plays a role in explaining the differences in behavior. Another possible reason is based on the fact that intellect captures how open-minded people are, a very similar personality trait captured by the NEO-PI-R five-factor model [Costa and McCrae 1992]. Therefore, it is expected that open-minded people will tend to have more information about their options for mobile phone service providers than people with lower scores of open-mindedness. Combining these observations with findings from our model, we claim that the more open-minded-high intellect-people are, the more they know about the mobile phone services they could have and hence the less satisfied they tend to be with the services they choose to use. This is in accordance with studies in psychology, as those presented by Schwartz in his book The Paradox of Choice - Why More is Less [Schwartz 2003].

The last personality trait that revealed a significant total effect on customer satisfaction was extroversion $\left(\beta_{71}=.16, p=.048\right.$ one-tailed test, $\beta_{71}^{\text {low }}=.001, \beta_{71}^{\text {up }}=.33,90 \%$ percentile-corrected confidence level). This result exemplifies when good usability does not directly translate into satisfaction. Although the total effect was positive (.16), it was mainly due to the positive evaluation of the usability of mobile phone services $\left(\beta_{61}=.28, p=.004\right)$, given that the direct effect of extroversion on satisfaction was not relevant $\left(\beta_{71}=.05, p=.64\right)$. Several reasons could be pointed out for the nonsignificant direct effect. As previously mentioned, extroversion has a positive influence on mobile phone usage, which has a negative effect on satisfaction. Prior work has reported extroversion to positively influence job satisfaction [Judge et al. 2002], while no significant effect was found for patient satisfaction [Hendriks et al. 2006]. In terms of customer satisfaction with a mobile phone service, the closest work is that by Zhou and $\mathrm{Lu}$ [2011] in which they found extroversion to positively influence trust on mobile e-commerce acceptance. Although trust can be strongly correlated with satisfaction [Walter et al. 2000], they are different concepts and should be modeled separately. Our findings clarify that extroversion positively influences satisfaction, and that this effect is diminished by extroversion's positive impact on mobile phone usage, which negatively impacts satisfaction. Hence, one could envision ways to prevent overuse of 
mobile services in order to increase the positive impact of extroversion on customer satisfaction with these services.

In this section, we have addressed our second research question and discussed results for the five conceptual relationships of the validated model, which helped us to unveil various forms of influence that personality traits-and their facets-can have on customer satisfaction with mobile phone services.

\subsection{Limitations of the Study}

Our study was conducted in Mexico. Future work should verify whether the presented model could be generalized to other countries and cultures. Additionally, we believe that qualitative interviews with participants of the study could have clarified, complemented, and shed additional light on these findings. However, our recruitment procedure ensured complete anonymity of our participants and hence we could not directly contact any participant, thus preventing a more in-depth exploration of the validated model. Nevertheless, our work provides a strong motivation for further qualitative studies to shed light on the reasons why some relationships proved significant in the model. Finally, our findings are based on mobile services that include phone calls, messages (SMS and MMS), and basic GPRS/3G-related services accessed by mostly feature phone users (only $7.1 \%$ were smart phone users). Future work shall expand the scope to contextual services typically offered for smart phone users with data plans.

\section{IMPLICATIONS FOR DESIGN}

The conceptual model validated in the previous section contributes to our understanding of how HCI practitioners can leverage the user's personality in the design of better mobile phone services. In this section, we summarize the insights that can be drawn from the results of our user study. We expect that the practical relevance of these insights will increase as techniques for the automatic assessment of personality are more accurate and pervasive [Saati et al. 2005; Khan et al. 2008; de Oliveira et al. 2011].

\subsection{Consider Personality-Based Personalization}

The significant total effect of extroversion, conscientiousness, and intellect on satisfaction supports the idea of personality-based personalization. Mobile services cannot change people's personality, but they could certainly address issues that lead a certain group of users (i.e., users with certain personality traits) to be unsatisfied. In order to explain its practical implementation, let's consider the negative effect of intellect on satisfaction. As previously mentioned, users with higher scores in the intellect trait are more likely to experience "the paradox of choice" [Schwartz 2003], that is, the more they know about their options, the less satisfied they tend to be with their choices. Mobile service providers could include recommendation algorithms to help these users manage their multiplicity of choices by providing ways to find out, easily compare, and choose among relevant options for their phone services (e.g., voice/data plans).

Recent work by Cherubini et al. [2011] has revealed that the lack of personalization is actually one of the biggest barriers for the adoption of today's mobile phone contextual services. Our findings support these conclusions and further identify new opportunities for personality-based personalization.

As an example of embodiment of this design principle, we can think of a service that monitors the calling behavior of the customer and recommends the most convenient call plan and options based on his/her communication patterns. Such a service might rank the proposed plan options based on the amount of money saved if one of the suggested plans were active. 


\subsection{Focus on Efficiency of Basic Mobile Communication Services}

According to our model, the perceived usability of the mobile phone services used by the participants of our study (mainly calls, messages, and basic GPRS/3G services) was the most important factor when explaining their satisfaction with them. Moreover, the concept of usability was mostly characterized by efficiency $\left(R^{2}=.70\right)$ rather than utility $\left(R^{2}=.43\right)$ and ease of use $\left(R^{2}=.35\right)$, thus highlighting an important trend for satisfaction. Note that saving people's time is a recurrent result from our research as mobile phone usage had a significant negative effect on satisfaction.

Next, we propose three design solutions that also take into account our first implication.

-Minimize disruption of the users' routine. Project managers in charge of developing mobile communication services should focus their efforts on designing more efficient solutions that minimize disruption of the users' routine. For instance, we can think about leaving the possibility to request statements of the monthly bill or performing operations on the contract such as enabling (or disabling) options of the call plan via SMS or email instead of requesting the customers to go through call centers that too often require an enormous effort from their side. Intuitive Web interfaces for online account management could also minimize the users' burden. In terms of minimizing routine disruption, the user's contextual information could be leveraged in order to identify the most suitable periods of the day to synchronously contact them.

-Support "special" users in managing their mobile phone usage time. Personalized services could be created to help users with low scores on the extroversion and conscientiousness traits better manage their time when overusing basic mobile phone services. For example, less organized people could overuse mobile services during a certain time period without planning much for the additional costs and end up with an unpleasant surprise when receiving their monthly bill. Mobile services with personality-based user models should probe these "less organized" users on their preferred maximum expenses for monthly phone bills, and send them periodic feedback on how close to this threshold they are. Additionally, the service could provide suggestions to these users on how to contact peers in a more efficient way.

-Identify and provide awareness on the technology consumption saturation point. Our validated model revealed that overusing mobile phone services might lead to lower satisfaction. This could indicate that customers of these services have a technology consumption saturation point. Further research should be conducted in order to develop methodologies for identifying this saturation point. Once this critical point is identified for each customer, persuasive techniques (e.g., social support, reminders, etc.) could be leveraged towards preventing mental/physical stress and hence low satisfaction.

\subsection{Balance Personality Traits across Samples in Iterative User Studies}

For several years the design of interactive products has been performed as an iterative process that commonly assesses usability in multiple evaluation phases. Users are often involved in these evaluations, thus requiring a consistent sampling methodology to avoid biases in the selection of users and hence in the findings of the studies. Currently, concerns with balancing samples mainly address the users' demographics (i.e., gender, age, socio-economic status, etc.) and background in relation to the context of the product being evaluated (e.g., in the case of a mobile service: experience with mobile phones, frequency of use, etc.). However, our study reveals a significant influence of people's personality traits on their perception of usability of the mobile phone services they use, which highlights the importance of also considering personality when balancing samples from iterative user studies. We therefore suggest HCI practitioners to preserve 
a similar personality distribution across samples whenever comparing user studies deployed for a given mobile phone service. Finally, also consider that results of these studies will lose generalization power if the personality distribution of the sample is significantly different from the personality distribution of the actual audience of the service.

\section{CONCLUSIONS AND FUTURE WORK}

We have proposed and validated a conceptual model that explains the influence of the users' personality on their satisfaction with basic mobile phone services (i.e., making/receiving calls, sending/receiving text messages, and using simple GPRS/3G services on prepaid phones). The relationship is measured both directly and indirectly by means of two mediators: actual mobile phone usage and perceived usability of the services. Our findings confirm that the higher the mobile phone services' perceived usability (measured in terms of usability goals including efficiency to use, utility, and easy of use), the more satisfied users will be with them. Moreover, those who like to meet new people-extroversion trait-and are more organized-conscientiousness trait-tend to be more satisfied with these communication services. Conversely, mobile phone usage and the intellect trait revealed a negative impact on customer satisfaction. Key messages of the model suggested personality-based personalization of mobile phone services and the need to balance personality traits across samples in iterative user studies. Implementation of these implications would certainly benefit from faster and less intrusive personality assessment techniques than the standard survey approach. Nevertheless we expect that today's personality prediction models [Saati et al. 2005; Khan et al. 2008; de Oliveira et al. 2011] will soon become more pervasive and encourage the emergence of yet new approaches. In terms of future work, we plan on carrying out a similar study in a different country to evaluate cultural effects. We are also working on personality prediction models from behavioral data.

\section{REFERENCES}

AJzen, I. 1991. The theory of planned behavior. Org. Behavior Hum. Decis. Process. 50, 179-211.

AlsajJan, B. A. 2010. How the big five personality dimensions influence customers trust in uk cellular providers? Int. J. Global Bus. 3, 1, 102-116.

Anderson, J. AND Gerbing, D. 1988. Structural equation modeling in practice: A review and recommended two-step approach. Psychol. Bull. 103, 3.

Antoniou, A. And Lepouras, G. 2010. Modeling visitors' profiles: A study to investigate adaptation aspects for museum learning technologies. J. Comput. Cult. Herit. 3, 7:1-7:19.

BAGOZZI, R. AND YI, Y. 1988. On the evaluation of structural equation models. J. Acad. Market. Sci. 16, 1, 74-94.

Blunch, N. J. 2008. Introduction to structural equation modelling using spss and amos. ACM Trans. Comput.Hum. Interact. 20, 2, 1-22.

Butt, S. And Phillips, J. G. 2008. Personality and self reported mobile phone use. Comput. Hum. Behav. 24, $2,346-360$.

Chen, W., Huang, H., And Chou, S.-C. T. 2008. Understanding consumer recommendation behavior in a mobile phone service context. In Proceedings of the European Conference on Information Systems (ECIS'08). 47.

Cherubini, M., De Oliveira, R., Hiltunen, A., And Oliver, N. 2011. Barriers and bridges in the adoption of today's mobile phone contextual services. In Proceedings of the $13^{\text {th }}$ International Conference on Human Computer Interaction with Mobile Devices and Services (MobileHCI'11). ACM Press.

Cheung, G. W. And Rensvold, R. B. 2002. Evaluating goodness-of-fit indexes for testing measurement invariance. Struc. Equation Model. 9, 1, 233-255.

Chittaranjan, G., Blom, J., and Gatica-Perez, D. 2011. Who's who with big-five: Analyzing and classifying personality traits with smartphones. In Proceedings of the International Symposium on Wearable Computing (ISWC'11). 8.

Costa, P. T. And Mccrae, R. R. 1992. NEO PI-R: Professional Manual/With Bibliography. Psychological Assessment Resources. 
CUPANI, M. 2009. El cuestionario de personalidad IPIP-FFM: Resultados preliminares de una adaptaci on en una muestra de preadolescentes argentinos. Perspectivas en Psicologıa 6, 51-58.

DAvis, F. D. 1989. Perceived usefulness, perceived ease of use, and user acceptance of information technology. MIS Quart. 13, 3, 319-340.

De Oliveira, R., Karatzoglou, A., Concejero, P., Armenta, A., and Oliver, N. 2011. Towards a psychographic user model from mobile phone usage. In Extended Abstracts on Human Factors in Computing Systems (CHI'11). ACM Press, New York, 2191-2196.

Devaraj, S., EAsley, R. F., AND CRANT, J. M. 2008. How does personality matter? Relating the five-factor model to technology acceptance and use. Inf. Syst. Res. 19, 1, 93-105.

Eckschlager, M., Bernhaupt, R., AND Tscheligi, M. 2005. NEmESys: Neural emotion eliciting system. In Extended Abstracts on Human Factors in Computing Systems (CHI'05). ACM Press, News York, 13471350.

Fishbein, M. And Ajzen, I. 1975. Belief, Attitude, Intention, and Behavior: An Introduction to Theory and Research. Addison-Wesley, Reading, MA.

ForNell, C. AND LARCKER, D. F. 1981. Structural equation models with unobservable variables and measurement error: Algebra and statistics. J. Market. Res. 18, 1, 382-388.

FrøkJÆr, E., Hertzum, M., And HornbæK, K. 2000. Measuring usability: Are effectiveness, efficiency, and satisfaction really correlated? In Proceedings of the SIGCHI Conference on Human Factors in Computing Systems (CHI'00). ACM Press, New York, 345-352.

GoldBerg, L. R. 1992. The development of markers for the big-five factor structure. Psych. Assess. 4, 26-42.

Goldberg, L. R. 1999. Personality Psychology in Europe. Vol. 7. Tilburg University Press, Tilburg, The Netherlands, 7-28.

Goldberg, L. R., Sweeney, D., Merenda, P. F., And Hughes, J. 1998. Demographic variables and personality: The effects of gender, age, education, and ethnic/racial status on self-descriptions of personality attributes. Pers. Indiv. Differences 24, 393-403.

Graziola, I., Pianesi, F., Zancanaro, M., and Goren-Bar, D. 2005. Dimensions of adaptivity in mobile systems: Personality and people's attitudes. In Proceedings of the $10^{\text {th }}$ International Conference on Intelligent Users Interface (IUI'05). ACM Press, New York, 223-230.

Hendriks, A., Smets, E., VRielink, M., VAN Es, S., ANd De HaEs, J. 2006. Is personality a determinant of patient satisfaction with hospital care? Int. J. Qual. Health Care 18, 2, 152-158.

Heo, J., Ham, D.-H., Park, S., Song, C., AND Yoon, W. C. 2009. A framework for evaluating the usability of mobile phones based on multi-level, hierarchical model of usability factors. Interact. Comput. 21, 263-275.

Holtgraves, T. 2011. Text messaging, personality, and the social context. J. Res. Personality 45, 1, 92-99.

HornbeK, K. and LaI-Chong LaW, E. 2007. Meta-analysis of correlations among usability measures. In Proceedings of the SIGCHI Conference on Human Factors on Computing Systems (CHI'07). ACM Press, New York, 617-626.

Hu, L. And Bentler, P. 1999. Cutoff criteria for fit indexes in covariance structure analysis: Conventional criteria versus new alternatives. Struct. Equation Model. 6, 1, 1-55.

Judge, T., Heller, D., AND Mount, M. 2002. Five-factor model of personality and job satisfaction: A metaanalysis. J. Appl. Psych. 87, 1, 530-541.

Khan, I., Brinkman, W.-P., Fine, N., and Hierons, R. 2008. Measuring personality from keyboard and mouse use. In Proceedings of the $15^{\text {th }}$ European Conference on Cognitive Ergonomics: The Ergonomics of Cool Intention (ECCE'08). ACM Press, New York, 1-8.

LeE, K. AND NASs, C. 2003. Designing social presence of social actors in human computer interaction. In Proceedings of the SIGCHI Conference on Human Factors in Computing Systems (CHI'03). ACM Press, New York, 289-296.

Mackinnon, D., Lockwood, C., Hoffman, J., West, S., And Sheets, V. 2002. A comparison of methods to test the significance of the mediated effect. Psych. Methods 7, 1, 83-104.

Nielsen, J. 1993. Usability Engineering. Morgan Kaufmann Publishers, San Francisco, CA.

Nielsen, J. AND Levy, J. 1994. Measuring usability: Preference vs. performance. Comm. ACM 37, 4, 66-75.

Niklas, S. AND Strohmeier, S. 2011. Exploring the impact of usefulness and enjoyment on mobile service acceptance: A comparative study. In Proceedings of the Hawaii International Conference on System Sciences (HICSS'11). 1-10.

Nunes, M., CERri, S., AND Blanc, N. 2008. Towards user psychological profile. In Proceedings of the $8^{\text {th }}$ Brazilian Symposium on Human Factors in Computing Systems (IHC'08). Sociedade Brasileira de Computacao, 196-203. 
Olsson, U. H., Foss, T., Troye, S. V., And Howell, R. D. 2000. The performance of ml, gls, and wls estimation in structural equation modeling under conditions of misspecification and nonnormality. Struc. Equation Model. 7, 4, 557-595.

Paunonen, S. and Ashton, M. 2001. Big five factors and facets and the prediction of behavior. J. Pers. Social Psych. 81, 3, 524-539.

Pianesi, F., Mana, N., CAPpelletti, A., Lepri, B., And Zancanaro, M. 2008. Multimodal recognition of personality traits in social interactions. In Proceedings of the $10^{\text {th }}$ International Conference on Multimodal Interfaces (IMCI'08). ACM Press, New York, 53-60.

Rogers, Y., Sharp, H., AND Preece, J. 2011. Interaction Design: Beyond Human-Computer Interaction 3rd Ed. Wiley.

Ryckman, R. M. 2004. Theories of Personality $8^{\text {th }}$ Ed. Brooks/Cole, Pacific Grove, CA.

SAATI, B., SAlEm, M., AND BRINkmAN, W. 2005. Towards customized user interface skins: Investigating user personality and skin colour. In Proceedings of the $11^{\text {th }}$ International Conference on Human Computer Interaction. 89-93.

Santrock, J. W. 2008. A Topical Approach to Life-Span Development. McGraw-Hill, New York, 411-412.

Sathish, M., Santhosh Kumar, K., Naveen, K., and Jeevanantham, V. 2011. A study on consumer switching behaviour in cellular service provider: A study with reference to chennai. Far East J. Psych. Bus. 2, 2, 71-81.

Sawng, Y.-W., KIm, S.-H., Lee, J., And Young, S. 2011. Mobile service usage behavior in Korea: An empirical study on consumer acceptance of innovative technologies. Tech. Econ. Devel. Econ. 17, 1, 151-173.

Schumacker, R. and Lomax, R. 2004. A Beginner's Guide to Structural Equation Modeling $2^{\text {nd }}$ Ed. Vol. 1. Taylor and Francis.

Schwartz, B. 2003. The Paradox of Choice: Why More Is Less. Ecco Press, New York.

Thøgersen, J., Juhl, H., And Poulsena, C. 2003. Complaining: A function of attitude, personality, and situation. In Proceedings of the American Marketing Association, Marketing and Public Policy Conference.

Turel, O. AND SERENKo, A. 2006. Satisfaction with mobile services in canada: An empirical investigation. Telec. Policy 30, 5-6, 314-331.

Verkasalo, H. T. 2009. Ph.D. thesis, Faculty of Electronics, Helsinki University of Technology, Espoo, Finland.

Vigoda-Gadot, E. AND Meisler, G. 2010. Emotions in management and the management of emotions: The impact of emotional intelligence and organizational politics on public sector employees. Public Adm. Rev. 70, 1, 72-86.

Waber, B. N., Olguin, D. O., Kim, T., and Pentland, A. 2008. Organizational engineering using sociometric badges. In Proceedings of the Academy of Management Annual Meeting.

Walter, A., Helfert, G., AND Mueller, T. A. 2000. The impact of satisfaction, trust, and relationship value on commitment: Theoretical considerations and empirical results. In Proceedings of the $16^{\text {th }}$ Annual IMP Conference (IMP'00).

Zhou, T. AND Lu, Y. 2011. The effects of personality traits on user acceptance of mobile commerce. Int. J. Hum.-Comput. Int. 27, 6, 545-561.

Received December 2011; revised December 2012; accepted January 2013 